\title{
Adsorption Extraction of Chromium lons (III) with the Help of Bentonite Clays
}

\author{
Myroslav Malovanyy', Olga Palamarchuk², Iryna Trach³, Halyna Petruk4, \\ Halyna Sakalova4, Khrystyna Soloviy' ${ }^{4}$, Tamara Vasylinych ${ }^{4}$, \\ Ivan Tymchuk ${ }^{1 *}$, Nataliya Vronska ${ }^{1}$
}

1 Viacheslav Chornovil Institute of Sustainable Development, Lviv Polytechnic National University, S. Bandera Str. 12, Lviv, 79013, Ukraine

2 Educational and Scientific Institution of Pedagogy, Psychology, Training of Specialists of Higher Qualification, Vinnytsia Mykhailo Kotsiubynskyi State Pedagogical University, Ostrozhskogo St. 32, Vinnytsia, 21100, Ukraine

3 Institute of Ecology, Vinnytsia National Technical University, Khmelnytsky Highway 95, Vinnytsia, 21021, Ukraine

4 Natural Sciences and Geography Faculty, Vinnytsia Mykhailo Kotsiubynskyi State Pedagogical University, Vinnytsia, Ukraine

* Corresponding author's e-mail: i.s.tymchuk@gmail.com

\begin{abstract}
This work is dedicated to the development of scientific technologies of wastewater purification of different industrial enterprises from chrome ions through adsorption with the help of bentonite from Cherkasy field under dynamic conditions. The prospects and efficacy of bentonite clays application for wastewater purification are confirmed by their advantages over other sorbents, that is: they win in accessibility, cost, and possibility of regeneration and multiple applications. The level of wastewater purification during adsorption with a stationary sorbent layer under static conditions and under conditions of perfect mixing at different concentrations of chromium ions (III) and quantities of the dosed sorbent was determined. The significant difference in the purification level ranges from $70-87 \%$ and is more dependent on the stock concentration of chromium ions. It was found that the purification time of the same volumes of solutions for low concentrations is almost twice shorter under constant stirring, and of the same level at the stock concentrations of $1500 \mathrm{mg} / \mathrm{dm}^{3}$. The technological schemes of wastewater purification from the heavy metal ions contamination were developed.
\end{abstract}

Keywords: ecological safety, natural clay sorbents, bentonite, adsorption, ions of heavy metals, chromium ions.

\section{INTRODUCTION}

Nowadays, the solution of environmental problem in Ukraine is becoming more and more popular. The analysis of the ecological situation testifies that in spite of the decrease of manufacturing industry, the level of water pollution is still high. The wastewater and surface water pollution with ions of heavy metals is one of the most serious ecological problems, which now does not have a sufficiently effective solution.

The sources of water pollution with ions of heavy metals are wastewater from galvanic shops, machine-building factories, enterprises of mining, ferrous and non-ferrous metal industry. Heavy metals are included into fertilizers and pesticides and are discharged together with wastewater from agricultural lands. They reduce the quality of basins and make water unsuitable for usage either by people or flora and fauna [Malovanyy et al., 2013, Tymchuk et al., 2020].

Additionally, a serious cause of surface and groundwater pollution in Ukraine is the increase of sludge and landfills, which annually accumulate 1500 tons of solid waste. Potentially dangerous are storages and grounds where galvanic 
sludge of a number of industrial enterprises and large cities are situated, especially those containing galvanic sludge with lime milk precipitator (3rd danger class) and the sludge produced during electro-coagulating purification and using iron-containing reagents ( $2 \mathrm{nd}$ danger class). The heavy metals contained in galvanic sludge infiltrate into ground water, are washed out with the wastewater and are discharged into basins again. The accumulation of these compounds in the human body has a negative influence on basic microbiota vital functions. Apart from that, high concentration of heavy metals disables the water use in a number of technological processes [Khokhotva and Waara, 2010].

Ukrainian enterprises, which can be denoted as sludge collectors, contain million tons of liquid sludge waste, in which the concentration of heavy metal compounds greatly exceeds their content in natural ores. The very existence of the sludge collectors is a major threat to the environment due to the toxicity and aggressiveness of the contents, not to mention the huge capital and operating expenses.

Equally dangerous are household communal waste that in an insufficiently cleaned or generally untreated condition, come from inhabited areas to rivers, lakes, seas and then to the filtration fields. In addition to various chemical harmful substances, these wastes contain pathogens of various infectious diseases (paratyphoid, dysentery, viral hepatitis, and tularemia).

The main sources of wastewater pollution with ionic chromium (III) are galvanic shops of machine-building, instrument-making, automotive, manufacturing, textile and leather factories with chrome tanning, factories of chemical industry producing chromium alum. The wastewater of the leather industry contains a large number of soluble and insoluble compounds, characterized by objectionable odor, dark color, which are foamy and toxic. The level of pollution and the amount of wastewater, produced during the leather and fur material processing, depends on the leather and fur types, the production technology and, first of all, the preparatory process and tanning. The mass content of chromium ions (III) in the tannery wastewater can reach 3000 or even more $\mathrm{mg} / \mathrm{dm}^{3}$. Taking into account the toxicity of this metal, the wastewater containing its compounds, are the subject of obligatory purification before discharge into natural basins.
In surface waters, chromium compounds are found in dissolved and fluidized states, the proportion between which depends on the water composition, the temperature and the $\mathrm{pH}$ value. The fluidized compounds are sorbent ones mostly. The sorbents may be clays, ferric hydroxide, fumed calcium carbonate and remains of plant and animal organisms. In the dissolved state, chromium is contained in the form of chromates and dichromates. Under aerobic conditions, Cr (VI) goes over $\mathrm{Cr}$ (III), the salts of which hydrolyze under the neutral and alkaline condition with hydroxide relies. MPC for $\mathrm{Cr}(\mathrm{VI})-0.05$, for $\mathrm{Cr}$ (III) -0.5 $\mathrm{mg} / \mathrm{dm}^{3}$; The MPC of harmful substance for $\mathrm{Cr}$ (VI) is -0.001 , for $\mathrm{Cr}$ (III) $-0.005 \mathrm{mg} / \mathrm{dm}^{3}$ (Sabadash et al., 2017).

Today, the reprocessing of such wastewater has not been worked out yet. That is why waste accumulates in the biosphere, polluting groundwater and basins, turning the industrialized regions of Ukraine into the area of ecological disaster. Accidental emissions of such waters into the hydrosphere have catastrophic consequences for the living organisms. This significantly affects the quality of water: it loses its natural color, taste, and overall ionic composition. The constant increase of basins and wastewater pollution due to the anthropogenic impact require searching for new safe methods of their purification. The existing chemical and physicochemical purification methods of polluted water (reagent precipitation, coagulation, ozonation, chlorination), which are active in chemical aggression or physical impact on water, allow removing certain pollutants from it, often deteriorating the physical and chemical properties of water and disturbing the natural balance of the dissolved salts therein. Consequently, the improvement of existing methods, data, technologies and searching for new ones for water purification is of vital importance, because they allow minimizing the infiltration of heavy metal ions into the hydrosphere.

\section{MATERIALS AND METHODS}

An analysis of recent contributions indicates the practicability of using the adsorption methods for the wastewater purification from pollutants using natural dispersed minerals. The purification of aqueous solutions using dispersed sorbents meets many of the requirements of environmentally friendly and energy-efficient production. 
Large mineral resources, cheap excavating, easy preparation for transportation and use, opportunity to use waste sorbents in other technologies are the main advantages of using natural minerals [Malovanyy et al. 2019; Melnyk et al. 2105].

There are more than 110 bentonite deposits and occurrences within the territory of Ukraine. According to the official institution "State balance of stocks in Ukraine" there are six deposits (Gorbkivske, Kudrynske, Cherkaske, Kurtsivske, Berezhanske, Pyzhivske) the stocks of which in categories $\mathrm{A}+\mathrm{B}+\mathrm{C}_{1}$ come up to -60624 tons, $\mathrm{C}_{2}-$ 221 tons, balanced stocks in categories $\mathrm{B}+\mathrm{C}_{1}+\mathrm{C}_{2}$ come up to 1415 tons. Today, only three deposits are elaborated: Gorbkivske, Kudrynske, Cherkaske, which give $86 \%$ of total stocks amount in the country and the major percentage of bentonite raw materials production. Kurtsivske, Berezhanske, Pyzhivske are abandoned now.

The Cherkasy deposit of bentonite and paligorskite clays is located on the territory of Zvenigorod and Zhashkiv districts of the Cherkasy region and partly on the territory of the Tarashchan and Stavishchensk districts of the Kyiv region. Regionally, it is located in the central part of the Ukrainian Crystal Shield. The deposit of approximately $700 \mathrm{~km}^{2}$ has a continuous areal extend, except from the areas of erosion in river valleys and deep cloughs (Fig. 1).

The deposit was discovered in 1954, the clay stocks of productive thickness were estimated at 22 million tons, and its capacity at $0.5-43 \mathrm{~m}$. Its capacity was divided into five layers due to the initiative of discoverers. The first layer consists of polymineral clay with great carbonate mass content. This layer has massive occurrence and the average width within the deposit $14.1 \mathrm{~m}$. The second layer has the average width of $5.9 \mathrm{~m}$, consisting mostly of bentonite clay and has the most economical value among other layers. The third layer has four main lenses and the average capacity 2.7 $\mathrm{m}$. It consists of the palygorskite clay. The capacity of the fourth layer is $1.7 \mathrm{~m}$., which consists of a genetic blend of bentonite and palygorskite. The fifth layer is the lowest part of the deposit productive thickness, which lies in the form of separate lenses. This layer has the average capacity $2.3 \mathrm{~m}$. and consists of hydromica with sand and montmorillonite impurities [Warchoł and Petrus, 2006].

The bentonite (type 2:1) from the Cherkasy deposit of bentonite and palygorskite clays was used for the investigations. In the structure of 2:1 type, montmorillonite crystals comprise two layers of silicon oxygen tetrahedron connected by the layer of aluminum-hydroxy-oxygen tetrahedron. The tetrahedral positions are filled in with silicium cation. In the case of the substitution of its cation parts, the aluminum deficiency in the positive charges, which arises, is compensated by the exchangeable cation $\left(\mathrm{Ca}^{2+}, \mathrm{K}^{+}, \mathrm{Na}^{+}\right)$, which are split between the layers.

\section{RESULTS AND DISCUSSION}

The preparatory process includes three stages. The raw material was crushed and dried in a drying chamber at a temperature of $120^{\circ} \mathrm{C}$ for 45

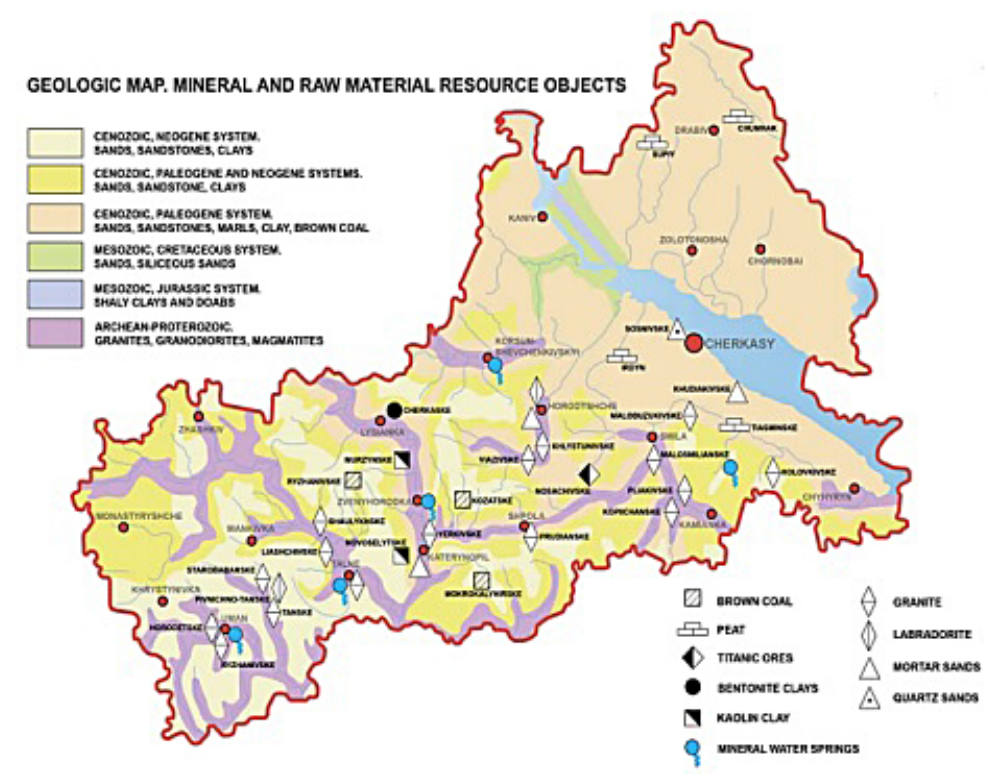

Figure 1. Map of the Cherkasy region 


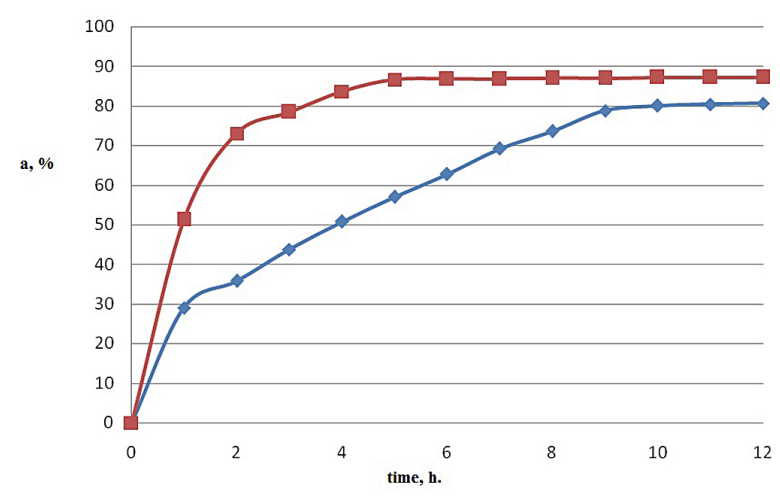

Figure 2. Change in the level of chromium ions (III) adsorption in the time interval of $0-12$ hours: static conditions; - - - perfect stirring conditions

minutes. Then clay was rubbed and divided into corresponding fractions [Warchoł et al., 2006]. In order to identify the adsorption potential of the bentonite clays of the Cherkasy deposit for chromium ions (III), the extraction processes were investigated in static mode and under constant stirring conditions. During the experiments such parameters as the layer of adsorbent - 5-20 g, the concentration of the initial solution $-0.5-2.0 \mathrm{~g} / \mathrm{dm}^{3}$, the duration of the sorption process study $-20 \mathrm{~min}-24$ hours [Malovanyy et al.2019], were studied.

The residual concentration of heavy metal ions was determined if wastewater with different concentrations of chromium ions (III) was absorbed on the same adsorbent layer. In figure (Fig. 2) the concentration of the initial solution of $\mathrm{Mex}^{+}$was $500 \mathrm{mg} / \mathrm{dm}^{3}$ is presented, the amount of dosed sorbent was $5 \mathrm{~g}$. The environmental temperature of the experiment was $20^{\circ} \mathrm{C}$; number of rotations $-70-80$ rotations per minute.

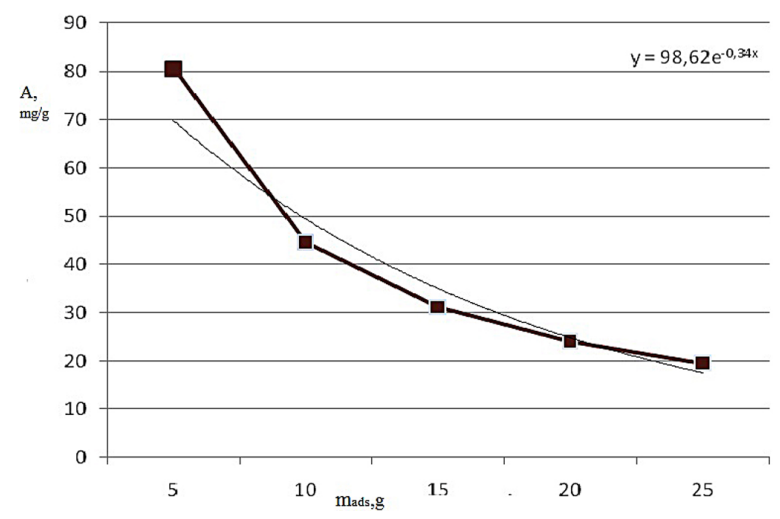

Figure 3. Dependence of chromium ions specific adsorption (A) from the sorbent mass
Sampling and analysis was performed hourly. A similar experiment was carried out for the initial concentrations of chromium ions of 1000-2000 $\mathrm{mg} / \mathrm{dm}^{3}$, with sorbent consumption of 10-20 g. The summarized results of the experiment are shown in Figures 3 and 4.

In general, the results of the experiments show that the maximum heavy metal ions sorption occurs within 24 hours for the concentrations above $1000 \mathrm{mg} / \mathrm{dm}^{3}$ and $12-14$ hours for lower concentrations of static conditions; and under perfect stirring conditions, the residual concentration values remain almost unchanged after 6 hours of stirring. The maximum absorption occurs within 0.5-7 hours; however, under the concentrations of heavy metal ions in wastewater less than $500 \mathrm{mg} / \mathrm{dm}^{3}$, the adsorption process occurs more regularly. In the case of the metal ions concentration increasing and the same dosage of the sorbent, the adsorption efficacy decreases, since the saturation (filling) of the mineral surface with the adsorbate occurs, which confirms the surficial character of the sorption.

The given results indicate that for the studied concentrations, the absorption of chromium ions is $80.6 \%$ and $87.2 \%$ when the process is realized under stirring conditions. The maximum sorption is reached after 6 hours, which is to say that the process is speeded up at least twice. Similar results were obtained for the wastewater with concentrations of chromium ions (III) of $1.0-2.0 \mathrm{~g} / \mathrm{dm}^{3}$.

The next stage of the study was to determine the effect of the adsorbent amount (dose) on the depth of sorption. According to the figure and exponential dependencies, the adsorption efficacy increases alon with the adsorbent dose, which can be explained by the surface increase, where the process of sorption takes place. The functional lag of the specific adsorption increase from the increase of the adsorbent mass should be mentioned, which indicates the predominantly surficial character of the sorption. Such a parameter as the adsorbent dose cannot be universally determined by these dependencies. When considering the qualitative composition of the polluted water, the initial and desired final concentration of the pollutant in the aqueous phase, the amount of clay mineral consumed for purification may vary, but the average is $5-12.5 \mathrm{~g} / \mathrm{dm}^{3}$ under the conditions of the metal ions concentration 500 $\mathrm{mg} / \mathrm{dm}^{3}$, and increasing the dose above the specified value is ineffective. 


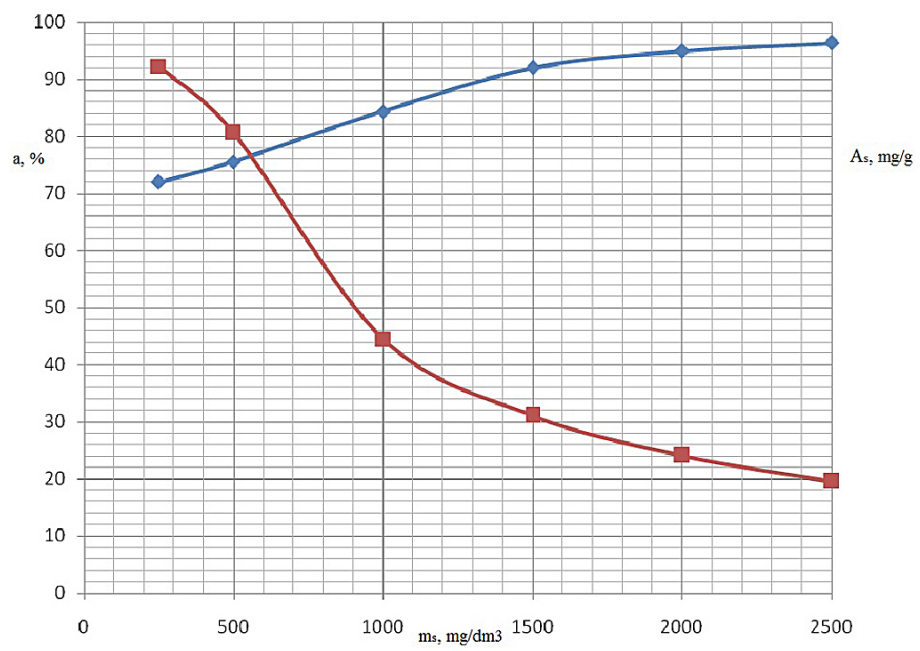

Figure 4. Rational adsorbent dose (ms) for chromium ions adsorption from aqueous medium: ——— special adsorption; —— adsorption efficacy

In order to determine the technologically rational parameters such as a dose of powdered sorbent, we have combined the dependence of specific adsorption and the efficacy of purification on the amount of adsorbent. Curve crossing will show the rational amount of the dosed sorbent (Fig. 4).

As can be seen from the figure above, the dosing of 5-8 g of sorbent per $1 \mathrm{dm}^{3}$ of polluted water is rational (in the case where the initial concentration of the pollutant does not exceed 1000 $\mathrm{mg} / \mathrm{dm}^{3}$ ). If the heavy metal ions have higher concentration, it is advisable to increase the dosage of the sorbent to $10-20 \mathrm{~g}$.

The studies of the wastewater purification process from chromium ions (III) by adsorption on bentonite under the conditions of a fixed layer of adsorbent were also carried out with the similar pollutant concentrations. Water was purified on a laboratory adsorption column with a diameter of $35 \mathrm{~mm}$ and a height of $300 \mathrm{~mm}$ using natural bentonite clay. The prepared clay was poured into a column. The prepared clay was poured into a column. The total weight of the sorbent in the adsorption column is $15-25 \mathrm{~g}$. The sorbent volume in the column is $21.6 \mathrm{~cm}^{3}$ and $29 \mathrm{~cm}^{3}$ accordingly to the sorbent weight of 15 and $20 \mathrm{~g}$. The solutions containing the $\mathrm{Cr}^{3+}$ ions of the given concentration were passed through the column. During the sorption samples were taken every $10 \mathrm{~cm}^{3}$; the concentration of $\mathrm{Cr}^{3+}$ ions in the solution was determined with the titrimetric method.

In order to establish the range of mode parameters, which require a detailed study of adsorption processes, a series of preliminary experiments was performed, which enabled to draw the following preliminary conclusions: temperature fluctuation from +10 to $+30^{\circ} \mathrm{C}$ has no significant effect on the absorption rate of $\mathrm{Cr}^{3+}$ bentonite ions [Sakalova et al. 2019].

1) The optimal average pumping rate of the standardized solution through the adsorption column of the given height is $0.3-0.5 \mathrm{~cm}^{3} /$ minute, at higher speed the amount of adsorbed $\mathrm{Cr}^{3+}$ decreases, and the lower speed increases the probability of a strong densifying of the pulp, which complicates the subsequent filtration processes;

2) the interval of the investigated concentrations $\left(0.5-2.0 \mathrm{~g} / \mathrm{dm}^{3}\right)$ of chromium ions was chosen based on practical considerations in accordance with the possible content of $\mathrm{Cr}^{3+}$ in real wastewater;

3 ) it is preliminary defined that complete saturation of bentonite clay with $\mathrm{Cr}^{3+}$ ions is achieved at the adsorbent layer of 15-20 g, for 1-3 days, depending on the standardized solution concentration.

The solutions were analyzed through each column volume $(\mathrm{OK})$, the average passage time was $3 \div 4$ minutes $/ \mathrm{cm}^{3}$, the control points were determined every $40 \mathrm{~cm}^{3}$ of the solution.

As the saturation curves of bentonite with chromium ions show (Fig. 5, 6), presented in the form of the dependence, the concentration of heavy metal ions at the outlet of the column $\left(\mathrm{C}_{\text {eff }}\right)$ from the volume of pumped standardized solutions $\left(\mathrm{V}_{\mathrm{eff}}\right)$, the adsorbent consumption has a significant influence on the conduit of the saturation 


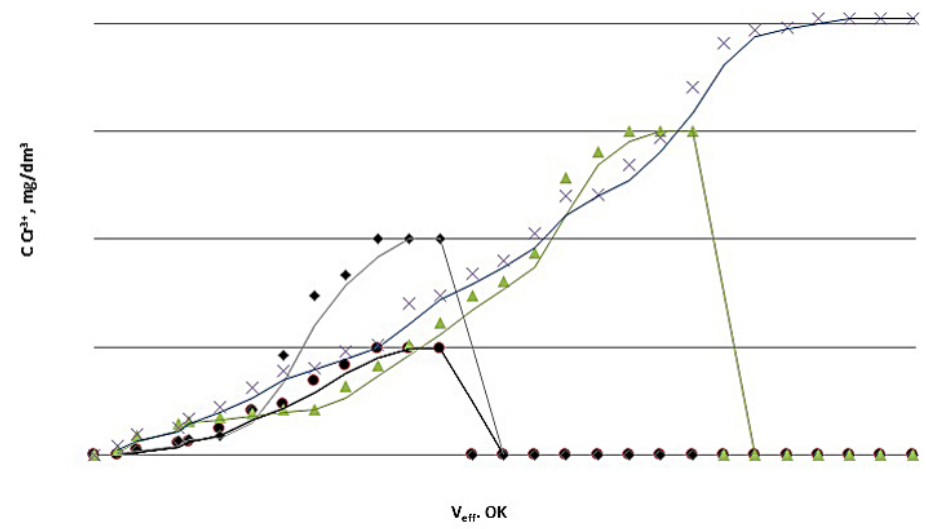

Figure 5. Curves of bentonite saturation weighing $15 \mathrm{~g}$ with a standardized solution with initial concentration of $\mathrm{Cr}^{3+}: \mathrm{g} / \mathrm{dm}^{3}: \bullet-0.5 ;-1 ; \boldsymbol{\Lambda}-1.5 ; \times-2.0$.

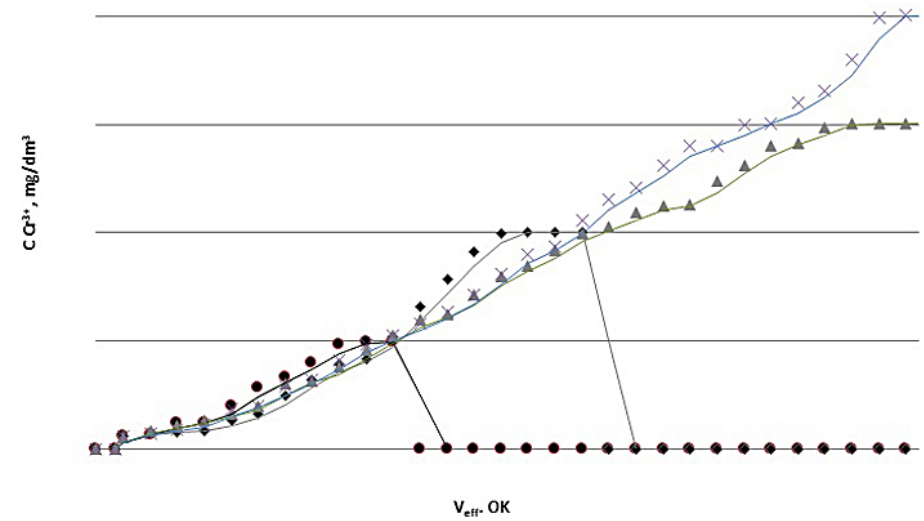

Figure 6. Curves of bentonite saturation weighing $20 \mathrm{~g}$ with a standardized solution with initial concentration $\mathrm{Cr}^{3+}: \mathrm{g} / \mathrm{dm}^{3}: \bullet-0.5 ;-1 ; \boldsymbol{\Lambda}-1.5 ; \times-2.0$

process. With the same chromium ions concentrations, the volume of the solution and the adsorption time before the full saturation of the adsorbent are much higher.
The most effective volume during the process of standardized solution pumping through a $15 \mathrm{~g}$. sorbent layer is 30.34 , and when a solution passes through $20 \mathrm{~g}$ of Sorbent, it is 41.4. These values

Table 1. Indicators of the sorption efficacy under the conditions of different initial chromium ions concentrations in the solution. Bentonite mass $15 \mathrm{~g}$

\begin{tabular}{|c|c|c|c|c|c|c|c|}
\hline \multirow{2}{*}{ № } & $\begin{array}{c}\text { Loading time } \\
\text { (t). min. }\end{array}$ & $\begin{array}{c}\mathrm{C}_{0}\left(\mathrm{Cr}^{3+}\right) \\
\mathrm{g} / \mathrm{dm}^{3}\end{array}$ & $\begin{array}{c}\text { First traces }\left(\mathrm{Cr}^{3+}\right) \text { in the } \\
\text { purified solution. OK }\end{array}$ & $\begin{array}{c}\text { Affective } \\
\text { volume } \\
\left(\mathrm{V}_{\text {eff }}\right) \text {. OK }\end{array}$ & $\begin{array}{c}\text { Dynamic } \\
\text { exchange } \\
\text { capacity }(\mathrm{T})\end{array}$ & $\mathrm{a}_{\max }$ & $\overline{\mathrm{a}}^{\mathrm{a}}$ \\
\hline 1 & 1080 & 0.5 & 1.39 & 11.03 & 0.001 & 95.6 & 82.2 \\
\hline 2 & 1230 & 1.0 & 1.39 & 12.41 & 0.002 & 97.5 & 81.0 \\
\hline 3 & 2480 & 1.5 & 0.92 & 23.45 & 0.002 & 98.6 & 74.0 \\
\hline 4 & 3205 & 2.0 & 0.92 & 31.72 & 0.003 & 98.9 & 63.5 \\
\hline
\end{tabular}

Table 2. Indicators of the sorption efficacy under the conditions of different initial chromium ions concentrations in the solution. Bentonite mass $20 \mathrm{~g}$

\begin{tabular}{|c|c|c|c|c|c|c|c|}
\hline \multirow{2}{*}{ №. } & \multirow{2}{*}{$\begin{array}{c}\text { Loading time } \\
\text { (t). min. }\end{array}$} & \multirow{2}{*}{$\begin{array}{c}\mathrm{C}_{0}\left(\mathrm{Cr}^{3+}\right) \\
\mathrm{g} / \mathrm{dm}^{3}\end{array}$} & $\begin{array}{c}\text { First traces }\left(\mathrm{Cr}^{3+}\right) \text { in the } \\
\text { purified solution. OK }\end{array}$ & $\begin{array}{c}\text { Affective } \\
\text { volume } \\
\left(\mathrm{V}_{\text {eff }}\right) . \text { OK }\end{array}$ & $\begin{array}{c}\text { Dynamic } \\
\text { exchange } \\
\text { capacity }(\mathrm{T})\end{array}$ & $\mathrm{a}_{\max }$ & $\overline{\mathrm{a}}$ \\
\hline 1 & 1380 & 0.5 & 1.03 & 13.79 & 0.0008 & 95.9 & 83.2 \\
\hline 2 & 2520 & 1.0 & 0.69 & 22.07 & 0.0010 & 97.8 & 80.2 \\
\hline 3 & 3720 & 1.5 & 0.69 & 38.06 & 0.0015 & 98.7 & 78.3 \\
\hline 4 & 4100 & 2.0 & 0.69 & 41.38 & 0.0020 & 98.9 & 70.2 \\
\hline
\end{tabular}


in both cases are observed for standardized solutions with the highest concentration of heavy metal ion, and confirm that the use of the adsorption method with the static sorbent layer to remove pollutants of low concentrations (less than $0.5 \mathrm{~g} / \mathrm{dm}^{3}$ ) is even possible under conditions of lower bentonite consumption. Moreover, with the initial concentration increase of chromium ions within the experimental values, the time, when the first traces of a pollutant appear at the outlet of the column, also increases, and the time to slip in all cases occurs quickly under the conditions of the pollutant concentration at the outlet of the column equal to $70 \%$ from the initial point. The exceptions are the dependence under the conditions of the chromium ions concentrations of 0.5 $\mathrm{g} / \mathrm{dm}^{3}-$ in this case, the concentration increase at the outlet of the column is linear.

According to the results of the experiment, the maximum chromium ions (III) absorption is $70.2-83.2 \%$ under the conditions of consumption of sorbent weighing $20 \mathrm{~g}$ and $63.5-82.2 \%$ in the case of sorbent mass $15 \mathrm{~g}$ (Table 1 and 2). The adsorption efficacy increases along with the adsorbent layer, and this statement can be explained by the development of the active sorption of the surface.

The small values of the dynamic exchange capacity are due to the fact that the first pollutant traces are already determined within 1-2 OK, and this value is much lower than in the case of pumping model solutions with ions of other pollutants [Sakalova et al. 2017; Sabadash et al. 2016], although the level of purification of the first volumes is high - $95.6-99 \%$ for solutions with different concentrations of $\mathrm{Cr}^{3+}$. The first chromium ions traces appear earlier when $20 \mathrm{~g}$ of bentonite is used and the values of the dynamic exchange capacity are somewhat lower when more adsorbent is used. However, the gain in the larger dynamic exchange capacity is small, if it is compared to the difference between volume pumping speeds. Thus, the difference between the volumes of pumped wastewater to "slip" is much higher when using $20 \mathrm{~g}$ of bentonite, and in the case when the concentrations are higher than $0.5 \mathrm{~g} / \mathrm{dm}^{3}$, the difference is 10 and even higher $\mathrm{OK}$.

The choice of the method of adsorption purification from heavy metal ions depends first of all on the equipment available at the enterprise. However, our experiments indicate that the consumption of sorbent under constant mixing conditions is lower under the same conditions of the experiments, especially at low concentrations $\left(500 \mathrm{mg} / \mathrm{dm}^{3}\right)$. However, no significant difference in the purification level was observed for either method; this value ranges from $70-87 \%$ and is more dependent on the initial chromium ions concentration. As for the duration of the process, it can be noted that the purification time of the same volumes of solutions for low concentrations is almost half shorter under the conditions of constant stirring, and of the same order under the conditions of initial concentrations is $1500 \mathrm{mg} /$ $\mathrm{dm}^{3}$. This "time alignment" can be explained by the significant increase in effective volume during the purification in the adsorption column.

\section{CONCLUSIONS}

The efficacy of the natural mineral sorbents use, in particular bentonite clays, for wastewater purification is confirmed by their advantages over other sorbents, which is: they have benefits in availability, cost, regeneration and multiple applications. Studies confirmed the prospect of using bentonite clays for the wastewater purification from chromium ions (III) by adsorption with a fixed layer of sorbent.

According to the results of the experiment, the efficacy of adsorption increases along with the layer of adsorbent. The degree of wastewater purification during adsorption with the fixed sorbent layer, under static conditions and under the conditions of perfect mixing with different chromium ions (III) concentrations and quantities of the dosed sorbent were determined. No significant difference in the purification levels was observed for either method; this value ranges from $70-87 \%$ and is more dependent on the initial concentration of the chromium ions.

\section{REFERENCES}

1. Khokhotva O., Waara S. 2010. The influence of dissolved organic carbon on sorption of heavy metals on urea-modified pine bark. Journal of Hazardous Materials, 173, 689-696.

2. Malovanyy M., Sakalova H., Vasylinycz T., Palamarchuk O., Semchuk J. 2019. Treatment of Effluents from Ions of Heavy Metals as Display of Environmentally Responsible Activity of Modern Businessman. Journal of Ecological Engineering, 4 (20), 167-176. 
3. Malovanyy M.S., Shmandiy V.M., Kharlamova O.V., Chelyadin L.I., Sakalova G.V. 2013. Analysis and systematization of existing methods for assessing the degree of environmental hazard. Environmental Safety, 1(15), 37-44.

4. Melnyk L., Bessarab A., Matko S., Malovanyy M. 2015. Adsorption of heavy metals ions from liquid media by palygorscite. Chemistry \& Chemical Technology, 9(4), 467-470.

5. Sabadash V., Gumnitski J., Hywluyd A. 2016. Mechanism of phosphates sorption by zeolites depending on degree of their substitution for potassium ions. Chemistry \& Chemical Technology, 10(2), 235-240.

6. Sabadash V., Gumnitsky J., Mylanyk O., Romaniuk L. 2017. Concurrent sorption of copper and chromium cations by natural zeolite. Environmental Problems, 2(1), 159-162.

7. Sakalova G., Vasylinycz T., Koval N., Kashchei V. 2017. Investigation of the metod of chemical desorption for exstraction of nikel ions (II) from bentonite clays. Enviromental Problems, 2(4), 187-190.

8. Sakalova H., Palamarchuk O., Vasylinycz T., Petrushka K., Zaharko J., Stocaluk O. 2019. SocioPsychological Essence of Attractiveness for the Subjects of Entrepreneurial Activities of Adsorption Extraction of Nickel Ions (II) by bentonite clays. Enviromental Problems,.4(2), 68-74.

9. Tymchuk I., Shkvirko O., Sakalova H., Malovanyy M., Dabizhuk T., Shevchuk O., Matviichuk O., Vasylinych T. 2020. Wastewater a Source of Nutrients for Crops Growth and Development. Journal of Ecological Engineering, 5 (20), 88-96.

10. Warchoł J., Misaelides P., Petrus R., Zamboulis D. 2006. Preparation and application of organo modified zeolitic materiał in removal of chromates and iodides.: Hazard. Mat, B137, 1410-1416.

11. Warchoł J., Petrus R. 2006. Modeling of heavy metal removal dynamics in clinoptilolite packed beds. Microporous and Mesoporous, 93(1-3), 29-39. 